\title{
Vibrational Spectroscopy and Density Functional Theory of Transition-Metal Ion-Benzene and Dibenzene Complexes in the Gas Phase
}

\author{
Todd D. Jaeger, ${ }^{\dagger}$ Deniz van Heijnsbergen, ${ }^{\ddagger}$ Stephen J. Klippenstein, $\$$ \\ Gert von Helden, ${ }^{\ddagger, \|}$ Gerard Meijer,,,$\| l$ and Michael A. Duncan ${ }^{*}, \dagger$ \\ Contribution from the Department of Chemistry, University of Georgia, Athens, Georgia 30602, \\ FOM Institute for Plasmaphysics Rijnhuizen, Edisonbaan 14, \\ NL-3439 MN Nieuwegein, The Netherlands, Combustion Research Facility, \\ Sandia National Laboratory, Mail Stop 9055, P.O. Box 969, Livermore, California 94550, and \\ Fritz-Haber-Institut der Max-Planck-Gesellschaft, Faradayweg 4-6, D-14195 Berlin, Germany
}

Received April 20, 2004; E-mail: maduncan@uga.edu

\begin{abstract}
Metal-benzene complexes of the form $\mathrm{M}(\text { benzene })_{n}(\mathrm{M}=\mathrm{Ti}, \mathrm{V}, \mathrm{Fe}, \mathrm{Co}, \mathrm{Ni})$ are produced in the gas-phase environment of a molecular beam by laser vaporization in a pulsed nozzle cluster source. These complexes are photoionized with an ArF excimer laser, producing the corresponding cations. The respective mono- and dibenzene complex ions are isolated in an ion-trap mass spectrometer and studied with infrared resonance enhanced multiple-photon dissociation (IR-REMPD) spectroscopy using a tunable free electron laser. Photodissociation of all complexes occurs by the elimination of intact neutral benzene molecules, and this process is enhanced on resonances in the vibrational spectrum, making it possible to measure vibrational spectroscopy for size-selected complexes. Vibrational bands in the $600-1700 \mathrm{~cm}^{-1}$ region are characteristic of the benzene molecular moiety with systematic shifts caused by the metal bonding. The spectra in this solvent-free environment exhibit periodic trends in band shifts and intensities relative to the free benzene molecule that varies with the metal. Density functional theory calculations are employed to investigate the structures, energetics, and vibrational frequencies of these complexes. The comparison between experiment and theory provides fascinating new insight into the bonding in these prototypical organometallic complexes.
\end{abstract}

\section{Introduction}

Transition-metal-containing ion-molecule complexes that are produced, isolated, and studied in the gas phase provide models for metal-ligand interactions and metal ion solvation. ${ }^{1-4}$ Of these, metal-benzene ions have a special attraction because of their relevance for catalysis and biological processes,, 56 in addition to the fundamental importance that aromatic $\pi$-bonding has for organometallic chemistry. ${ }^{7,8}$ Metal ion-benzene complexes are also interesting because they form sandwich structures and can thus be compared to similar complexes synthesized and isolated in conventional synthetic chemistry. ${ }^{7,8}$ Infrared spec-

\footnotetext{
University of Georgia.

$\doteqdot$ FOM Institute for Plasmaphysics Rijnhuizen.

$\S$ Sandia National Laboratory.

"Fritz-Haber-Institut der Max-Planck-Gesellschaft.

(1) Gas Phase Inorganic Chemistry; Russell, D. H., Ed.; Plenum: New York, 1989.

(2) Eller, K.; Schwarz, H. Chem. Rev. 1991, 91, 1121-1177.

(3) Organometallic Ion Chemistry; Freiser, B. S., Ed.; Kluwer: Dordrecht, The Netherlands, 1996.

(4) Gas-Phase Metal Ion Chemistry (special issue), Leary, J. J., Armentrout, P. B., Eds.; Int. J. Mass Spectrom. 2001, 204, 1-294.

(5) (a) Ma, J. C.; Dougherty, D. A. Chem. Rev. 1997, 97, 1303-1324. (b) Dougherty, D. A. Science 1996, 271, 163-168.

(6) Caldwell, J. W.; Kollman, P. A. J. Am. Chem. Soc. 1995, 117, 41774178.

(7) Muetterties, E. L.; Bleeke, J. R.; Wucherer, E. J.; Albright, T. A. Chem. Rev. 1982, 82, 499-525.

(8) Long, N. J. Metallocenes; Blackwell Sciences: Oxford, U.K., 1998.
}

10.1021/ja0477165 CCC: $\$ 27.50$ @ 2004 American Chemical Society troscopy has frequently been applied to study condensed-phase metal-benzene sandwich complexes to investigate their bonding via spectral shifts of the ligand-based vibrations. ${ }^{9-11}$ However, until recently, such information has not been available for gas phase ion complexes. We have recently reported the application of infrared resonance-enhanced multiple-photon dissociation (IR-REMPD) as a method to obtain vibrational spectroscopy of metal ion-benzene complexes. ${ }^{12,13}$ In the present work, we apply this method to several cation-benzene complexes of the first-row transition metals to investigate the trends in their properties.

After the discovery of ferrocene ${ }^{14}$ and the explanation of its bonding stability through metal-ligand charge transfer, dibenzene chromium was synthesized as the first example of a metalbenzene sandwich complex, and its stability was understood via the familiar 18 -electron rule. ${ }^{15}$ Since that time, neutral metal-benzene complexes have been studied for many years

(9) Fritz, H. R. Adv. Organomet. Chem. 1964, 1, 239-317.

(10) Aleksanyan, V. T. Vib. Spectra Struct. 1982, 11, 107-167.

(11) Nakamoto, K. Infrared and Raman Spectra of Inorganic and Organometallic Compounds, 5th ed.; Wiley-Interscience: New York, 1997, Part B.

(12) van Heijnsbergen, D.; von Helden, G.; Meijer, G.; Maitre, P.; Duncan, M. A. J. Am. Chem. Soc. 2002, 124, 1562-1563.

(13) van Heijnsbergen, D.; Jaeger, T. D.; von Helden, G.; Meijer, G.; Duncan, M. A. Chem. Phys. Lett. 2002, 364, 345-351.

(14) Kealy, T. J.; Paulson, P. L. Nature 1951, 168, 1039-1040.

(15) Fischer, E. O.; Hafner, W. Z. Naturforsch. 1955, 10B, 665-668. 
in the condensed phase, as have some complexes with net charge that are produced and stabilized via counterions. ${ }^{7,8}$ In gas-phase studies, many metal ion-benzene species have been studied with mass spectrometry. ${ }^{16-21}$ Collision-induced dissociation, ${ }^{18}$ equilibrium mass spectrometry, ${ }^{19}$ and UV-vis photodissociation ${ }^{16,17}$ measurements have been employed to determine bond energies in these systems. Theory has examined the structures and energetics of these species. ${ }^{2,3,22-28}$ As shown by Kaya and co-workers, various metal-benzene complexes form fascinating multiple-decker sandwiches. ${ }^{20}$ Prominent $\mathrm{M}_{x}\left(\mathrm{C}_{6} \mathrm{H}_{6}\right)_{y}$ stoichiometries were observed by mass spectrometry at $x: y$ values where $y=x+1$, and this tendency was most pronounced for the early transition metals, especially vanadium. Bowers and coworkers probed the vanadium complexes with ion mobility measurements, confirming the multiple-decker sandwich structures. ${ }^{21}$ Photoelectron spectroscopy has been applied to metalbenzene anions, ${ }^{20 b, 29}$ and recently an IR absorption spectrum was obtained for $\mathrm{V}$ (benzene) $)_{2}$ that was size-selected as a cation and then deposited into a rare gas matrix and neutralized. ${ }^{30}$ Lisy and co-workers have reported infrared spectroscopy in the $\mathrm{C}-\mathrm{H}$ stretching region on alkali cation-benzene complexes. ${ }^{31}$ In two recent communications, we have shown how IR-REMPD can be employed to measure vibrational spectroscopy for metal mono- and dibenzene complexes. ${ }^{12,13}$ In work related to this, $\mathrm{Cr}^{+}$(aniline) complexes have been studied. ${ }^{32}$ The tunable free

(16) (a) Jacobson, D. B.; Freiser, B. S. J. Am. Chem. Soc. 1984, 106, 39003904. (b) Jacobson, D. B.; Freiser, B. S. J. Am. Chem. Soc. 1984, 106, 4623-4624. (c) Rufus, D.; Ranatunga, A.; Freiser, B. S. Chem. Phys. Lett. 1995, 233, 319-323.

(17) (a) Willey, K. F.; Cheng, P. Y.; Bishop, M. B.; Duncan, M. A. J. Am Chem. Soc. 1991, 113, 4721-4728. (b) Willey, K. F.; Yeh, C. S.; Robbins, D. L.; Duncan, M. A. J. Phys. Chem. 1992, 96, 9106-9111.

(18) (a) Chen, Y. M.; Armentrout, P. B. Chem. Phys. Lett. 1993, 210, $123-$ 128. (b) Meyer, F.; Khan, F. A.; Armentrout, P. B. J. Am. Chem. Soc. 1995, 117, 9740-9748. (c) Armentrout, P. B.; Hales, D. A.; Lian, L. In Cluster Reactions; Duncan, M. A., Ed.; Advances in Metal and Semiconductor Clusters Series; JAI Press: Greenwich, CT, 1994; Vol. 2, pp 1-40. (d) Rogers, M. T.; Armentrout, P. B. Mass Spectrom. Rev. 2000 $19,215-247$

(19) (a) Dunbar, R. C.; Klippenstein, S. J.; Hrusak, J.; Stöckigt, D.; Schwartz, H. J. Am. Chem. Soc. 1996, 118, 5277-5283. (b) Ho, Y. P.; Yang, Y. C.; Klippenstein, S. J.; Dunbar, R. C. J. Phys. Chem. A 1997, 101, 33383347 .

(20) (a) Hoshino, K.; Kurikawa, T.; Takeda, H.; Nakajima, A.; Kaya, K. J. Phys. Chem. 1995, 99, 3053-3055. (b) Judai, K.; Hirano, M.; Kawamata, H.; Yabushita, S.; Nakajima, A.; Kaya, K. Chem. Phys. Lett. 1997, 270, $23-$ 30. (c) Yasuike, T.; Nakajima, A.; Yabushito, S.; Kaya, K. J. Phys. Chem. A 1997, 101, 5360-5367. (d) Kurikawa, T.; Takeda, H.; Hirano, M.; Judai, K.; Arita, T.; Nagoa, S.; Nakajima, A.; Kaya, K. Organometallics 1999, 18, 1430-1438. (e) Nakajima, A.; Kaya, K. J. Phys. Chem. A 2000, 104, $176-191$

(21) Weis, P.; Kemper, P. R.; Bowers, M. T. J. Phys. Chem. A 1997, 101, 82078213 .

(22) (a) Sodupe, M.; Bauschlicher, C. W. J. Phys. Chem. 1991, 95, 86408645. (b) Sodupe, M.; Bauschlicher, C. W.; Langhoff, S. R.; Partridge, H. J. Phys. Chem. 1992, 96, 2118-2122. (c) Bauschlicher, C. W.; Partridge, H.; Langhoff, S. R. J. Phys. Chem. 1992, 96, 3273-3278. (d) Sodupe, M.; Bauschlicher, C. W. Chem. Phys. 1994, 185, 163-171.

(23) Stöckigt, D. J. Phys. Chem. A 1997, 101, 3800-3807.

(24) (a) Yang, C.-N.; Klippenstein, S. J. J. Phys. Chem. 1999, 103, 10941103. (b) Klippenstein, S. J.; Yang, C.-N. Int. J. Mass Spectrom. 2000, 201, 253-267.

(25) Chaquin, P.; Costa, D.; Lepetit, C.; Che, M. J. Phys. Chem. 2001, 105, $4541-4545$

(26) Pandey, R.; Rao, B. K.; Jena, P.; Alvarez Blanco, M. J. Am. Chem. Soc. 2001, 123, 3799-3808.

(27) Li, Y.; Baer, T. J. Phys. Chem. A 2002, 106, 9820-9826.

(28) Kaczorwska, M.; Harvey, J. M. Phys. Chem. Chem. Phys. 2002, 4, $5227-$ 5233.

(29) Gerhards, M.; Thomas, O. C.; Nilles, J. M.; Zheng, W.-J.; Bowen, K. H., Jr. J. Chem. Phys. 2002, 116, 10247-10252.

(30) Judai, K.; Sera, K.; Amatsutsumi, S.; Yagi, K.; Yasuike, T.; Nakajima, A.; Kaya, K. Chem. Phys. Lett. 2001, 334, 277-284.

(31) (a) Cabarcos; O. M.; Weinheimer, C. J.; Lisy, J. M. J. Chem. Phys. 1998 108, 5151-5154. (b) Cabarcos, O. M.; Weinheimer, C. J.; Lisy, J. M. J. Chem. Phys. 1999, 110, 8429-8435.

(32) Oomens, J.; Moore, D. T.; von Helden, G.; Meijer, G.; Dunbar, R. C. J. Am. Chem. Soc. 2004, 126, 724-725. electron laser provides high fluence and broad tunability in the infrared to make these experiments possible.

Although many transition-metal ion-benzene complexes have been studied, significant issues remain about their electronic structure and bonding. It is well-known that metal-ligand bonding can include both electrostatic and covalent components. Covalent interactions are complex in transition-metal systems because of the frequent occurrence of low-lying metal excited states that can mix with the ground state or compete with it for the most stable bonding configuration. Theory is often not able to distinguish between different electronic states and metal spin configurations to determine the ground states of these complexes. In the case of metal ion-benzene systems, it is not always clear that $\eta^{6} \pi$-bonding will be preferred. Strong metal binding interactions may distort benzene from its symmetric structure. In dibenzene sandwich species, staggered $\left(D_{6 h}\right)$ or eclipsed $\left(D_{6 d}\right)$ ligand conformations are possible. However, without detailed spectroscopy, it has not been possible to probe these details of the structure and bonding in any systematic way. Different electronic configurations and geometric structures can lead to different vibrational spectra, and thus IR spectroscopy may provide a probe of these structural details.

\section{Experimental Methods}

Transition metal-benzene complexes of the form $\mathrm{M}-\left(\mathrm{C}_{6} \mathrm{H}_{6}\right)_{n}(\mathrm{M}$ $=\mathrm{Ti}, \mathrm{V}, \mathrm{Fe}, \mathrm{Co}$, and $\mathrm{Ni}$ ) were produced by laser vaporization in a pulsed nozzle (Jordan) source using an argon expansion seeded with benzene vapor at ambient temperature. Neutral complexes in the molecular beam passed through the center of a quadrupole ion trap mass spectrometer (Jordan), and the corresponding cations were produced by photoionization with an ArF excimer laser (Neweks, PSX$100 ; 193 \mathrm{~nm} ; 6.42 \mathrm{eV} ; 4 \mathrm{~mJ} /$ pulse). The ionization potentials of all of the neutral metal-benzene complexes studied here have been measured previously, and these were lower than the ArF photon energy, so that a one-photon process could cause efficient ionization..$^{20}$ The density of ions produced in this experiment was far too low for IR absorption spectroscopy, and therefore we used IR photodissociation to measure the vibrational spectroscopy. The experimental methodology for IR photodissociation has been described previously in the study of polycyclic aromatic hydrocarbon ions, ${ }^{33} \mathrm{Ti}_{8} \mathrm{C}_{12}{ }^{+}$clusters, ${ }^{34}$ and both $\mathrm{V}^{+}\left(\mathrm{C}_{6} \mathrm{H}_{6}\right)_{1,2}$ and $\mathrm{Al}^{+}\left(\mathrm{C}_{6} \mathrm{H}_{6}\right)$ complexes. ${ }^{12,13}$ The cation complexes produced by photoionization were trapped for several milliseconds and isolated by mass with the RF potentials of the ion trap (1 MHZ; up to $\sim 1000 \mathrm{~V} \mathrm{p}-\mathrm{p}$ ). In our implementation of the ion trap, it was not possible to stabilize the trajectories of the trapped ions by the use of a collisional gas. Unfortunately, this prohibited absolute mass selection of specific ions. However, ions below a selected mass threshold could be rejected from the trap by adjustment of the RF potential. In these experiments, all molecules below the mass of interest were eliminated, allowing their fragments to be monitored on a zero background. For example, ions below $\mathrm{M}^{+}\left(\mathrm{C}_{6} \mathrm{H}_{6}\right)_{2}$ were eliminated to monitor the appearance of the $\mathrm{M}^{+}\left(\mathrm{C}_{6} \mathrm{H}_{6}\right)$ fragment.

Infrared excitation was accomplished with the tunable Free Electron Laser for Infrared eXperiments (FELIX) ${ }^{35}$ which delivers intense $10-$ $50 \mathrm{~mJ}$ pulses of infrared light throughout the spectral region of the main IR-active skeletal vibrations of benzene $\left(600-1700 \mathrm{~cm}^{-1}\right){ }^{36}$ After

(33) Oomens, J.; van Roij, A. J. A.; Meijer, G.; von Helden, G. Astrophys. J. 2000, 542, 404-410.

(34) van Heijnsbergen, D.; Duncan, M. A.; Meijer, G.; von Helden, G. Chem Phys. Lett. 2001, 349, 220-226.

(35) Oepts, D.; van der Meer, A. F. G.; van Amersfoort, P. W. Infrared Phys Technol. 1995, 36, 297-308.

(36) Shimanouchi, T. Molecular Vibrational Frequencies. In NIST Chemistry WebBook, NIST Standard Reference Database Number 69; Linstrom, P. J., Mallard, W. G., Eds.; National Institute of Standards and Technology: Gaithersburg, MD, July 2001. http://webbook.nist.gov, accessed April 2004 
excitation with FELIX, the contents of the ion trap were extracted into a time-of-flight spectrometer (Jordan) for mass analysis. Infrared absorption led to IR-REMPD. This was evident from the appearance of fragment ions following IR excitation. The infrared spectrum was obtained by monitoring the intensity of these fragment ions versus the frequency of the infrared laser.

\section{Theoretical Methods}

The molecular structures, harmonic vibrational frequencies, and infrared absorption intensities were calculated for a variety of transition metal-benzene monobenzene ("monomer") and dibenzene ("dimer") cation complexes using density functional theory (DFT). These calculations employed the Becke-3 Lee-Yang Parr (B3LYP) functional ${ }^{37}$ and the $6-311++\mathrm{G}(d, p)$ basis set. ${ }^{38}$ The transition-metal ions from $\mathrm{Ti}^{+}$ to $\mathrm{Cu}^{+}$were investigated. In each complex, the metal cations were assumed to bind to the central region of the benzene aromatic rings for both the monomer and dimer calculations. The dimers were assumed to exist in a sandwich structure, with the metal ions separating the two benzene rings. The metal ions were allowed to deviate from the $C_{6}$ symmetry axis as necessary to obtain all real frequencies. Similarly, reduced symmetries were considered as appropriate for the benzene rings. In one or two instances, one imaginary frequency remained even in $C_{1}$ symmetry, which was likely an artifact of the numerical methods employed in the calculations. A variety of electronic states were considered with the results presented expected to correlate with the ground electronic states. Spin-restricted wave functions were employed for the singlet states, while unrestricted wave functions were employed for all other electronic states. The density functional calculations were performed on a Parallel Quantum Solutions ${ }^{39}$ Linux cluster employing the Gaussian98 quantum chemistry software. ${ }^{40}$

\section{Results and Discussion}

Metal-benzene complexes with different transition metals were produced efficiently in the laser vaporization process, as we have described previously. ${ }^{12,17}$ Upon photoionization with ArF radiation, a mass distribution of $\mathrm{M}^{+}$(benzene) ${ }_{n}$ was obtained for values up to $n=6-8$, depending on the amount of benzene added. The benzene in this experiment was introduced into the expansion gas at its ambient vapor pressure, and it flows through the vaporization zone. There is therefore excess benzene vapor in the cluster growth region, and we primarily produce clusters of atomic metal cations surrounded by multiple benzene molecules, rather than complexes of benzene with larger metal clusters. We adjust the pressure to produce mainly the $n=1$, 2 complexes during infrared scans.

Figure 1 shows the mass spectra observed for vanadiumbenzene complexes and how the ions fragment upon irradiation with the infrared light when it is tuned to a resonance. Because of the characteristics of the ion trap, it is not possible to select only the $\mathrm{V}^{+}\left(\mathrm{C}_{6} \mathrm{H}_{6}\right)$ ion for study, since the RF potentials only allow elimination of masses below a certain threshold. In the

(37) Becke, A. D. J. Chem. Phys. 1993, 98, 5648-5652.

(38) Hehre, W. J.; Radom, L.; Pople, J. A.; Schleyer, P. v. R. Ab Initio Molecular Orbital Theory; Wiley: New York, 1987.

(39) Parallel Quantum Solutions (PQS) QS16-2000R Parallel QuantumStation.

(40) Frisch, M. J.; Trucks, G. W.; Schlegel, H. B.; Scuseria, G. E.; Robb, M A.; Cheeseman, J. R.; Zakrzewski, V. G.; Montgomery, J. A., Jr.; Stratmann, R. E.; Burant, J. C.; Dapprich, S.; Millam, J. M.; Daniels, A. D.; Kudin, K. N.; Strain, M. C.; Farkas, O.; Tomasi, J.; Barone, V.; Cossi, M.; Cammi, R.; Mennucci, B.; Pomelli, C.; Adamo, C.; Clifford, S.; Ochterski, J.; Petersson, G. A.; Ayala, P. Y.; Cui, Q.; Morokuma, K.; Malick, D. K.; Rabuck, A. D.; Raghavachari, K.; Foresman, J. B.; Cioslowski, J.; Ortiz, J. V.; Stefanov, B. B.; Liu, G.; Liashenko, A.; Piskorz, P.; Komaromi, I.; Gomperts, R.; Martin, R. L.; Fox, D. J.; Keith, T.; Al-Laham, M. A.; Peng, C. Y.; Nanayakkara, A.; Gonzalez, C.; Challacombe, M.; Gill, P. M. W.; Johnson, B. G.; Chen, W.; Wong, M. W.; Andres, J. L.; Head-Gordon, M.; Replogle, E. S.; Pople, J. A. Gaussian 98, revision A.11.2; Gaussian, Inc.: Pittsburgh, PA, 1998.

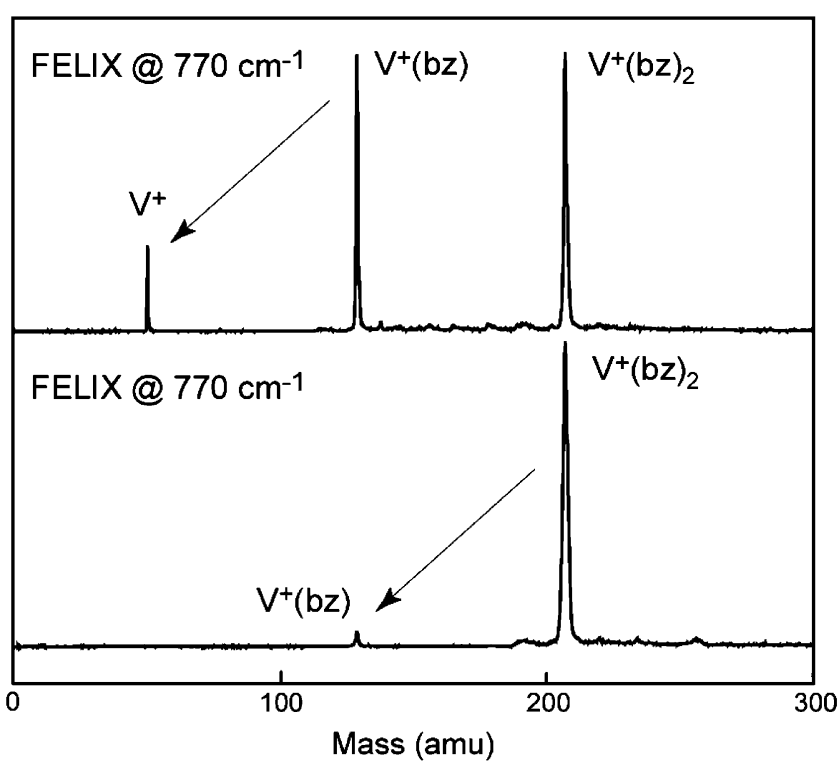

Figure 1. Mass spectra and fragment ions produced by IR-REMPD of trapped vanadium-benzene ions. In the upper trace, the RF potentials of the trap are adjusted so that all ions up to $\mathrm{V}^{+}(\mathrm{bz})$ are ejected before the IR laser fires. The $\mathrm{V}^{+}$mass peak appears as a result of IR-induced photodissociation. In the lower trace, all ions up to $\mathrm{V}^{+}(\mathrm{bz})_{2}$ are blocked before the laser. The $\mathrm{V}^{+}(\mathrm{bz})$ fragment appears following IR excitation. These measurements show that $\mathrm{V}^{+}$is the photofragment from $\mathrm{V}^{+}(\mathrm{bz})$ and $\mathrm{V}^{+}(\mathrm{bz})$ is the photofragment from $\mathrm{V}^{+}(\mathrm{bz})_{2}$.

upper trace, both $\mathrm{V}^{+}\left(\mathrm{C}_{6} \mathrm{H}_{6}\right)$ and $\mathrm{V}^{+}\left(\mathrm{C}_{6} \mathrm{H}_{6}\right)_{2}$ are present, but no masses below $\mathrm{V}^{+}\left(\mathrm{C}_{6} \mathrm{H}_{6}\right)$ are seen until the IR laser fires. After this, the $\mathrm{V}^{+}$ion appears as a fragment, but it is not yet clear which parent ion produced it. The situation is clarified, however, by the data in the lower trace, where ions below $\mathrm{V}^{+}\left(\mathrm{C}_{6} \mathrm{H}_{6}\right)_{2}$ are blocked before laser excitation. Only a small amount of $\mathrm{V}^{+}$. $\left(\mathrm{C}_{6} \mathrm{H}_{6}\right)$ appears here as a photofragment. In particular, it is evident that no $\mathrm{V}^{+}$fragment is produced from the $\mathrm{V}^{+}\left(\mathrm{C}_{6} \mathrm{H}_{6}\right)_{2}$ parent. $\mathrm{V}^{+}$and $\mathrm{V}^{+}\left(\mathrm{C}_{6} \mathrm{H}_{6}\right)$ are therefore the fragments from $\mathrm{V}^{+}$$\left(\mathrm{C}_{6} \mathrm{H}_{6}\right)$ and $\mathrm{V}^{+}\left(\mathrm{C}_{6} \mathrm{H}_{6}\right)_{2}$, respectively, and these fragments can be used to measure uniquely the dissociation spectra of their parent ions, as we have shown previously. ${ }^{12}$ This same methodology is employed for all of the $\mathrm{M}^{+}\left(\mathrm{C}_{6} \mathrm{H}_{6}\right)_{1,2}$ complexes studied here.

The dissociation energies of $\mathrm{V}^{+}\left(\mathrm{C}_{6} \mathrm{H}_{6}\right) \quad(55.8 \mathrm{kcal} / \mathrm{mol}$; $\left.\sim 19500 \mathrm{~cm}^{-1}\right)$ and $\mathrm{V}^{+}\left(\mathrm{C}_{6} \mathrm{H}_{6}\right)_{2}\left(58.8 \mathrm{kcal} / \mathrm{mol} ; \sim 20600 \mathrm{~cm}^{-1}\right)$ have been measured previously with collision-induced dissociation. ${ }^{18}$ It is therefore clear that photodissociation of these ions requires the input of many infrared photons. However, multiplephoton processes involving 100 or more photons have been measured previously with FELIX. ${ }^{41-43}$ We make the distinction between multiphoton processes, involving nonresonant absorption steps, and multiple-photon processes that involve resonant absorption, intramolecular vibrational relaxation (IVR), and continued resonant absorption within a single laser pulse. As discussed in our previous articles, ${ }^{41-43}$ the latter mechanism, which gives rise to rather efficient resonant enhancement on vibrational fundamentals, is believed to be active in the present study. This process is facilitated by the temporal profile of the

(41) (a) von Helden, G.; Holleman, I.; Meijer, G.; Sartakov, B. Opt. Express 1999, 4, 46-52. (b) von Helden, G.; Holleman, I.; Knippels, G. M. H.; van der Meer, A. F. G.; Meijer, G. Phys. Rev. Lett. 1997, 79, 5234-5237.

(42) van Heijnsbergen, D.; von Helden, G.; Duncan, M. A.; van Roij, A. J. A.; Meijer, G. Phys. Rev. Lett. 1999, 83, 4983-4986.

(43) van Heijnsbergen, D.; von Helden, G.; Meijer, G. J. Phys. Chem. A 2003, 107, 1671-1688. 
Table 1. Positions of the IR Bands Observed for Transition-Metal Ion-Benzene Complexes and Their Comparison to the Spectra of Neutral Complexes and to the Predictions of Theory

\begin{tabular}{|c|c|c|c|c|c|c|c|c|}
\hline \multirow[b]{2}{*}{ complex } & \multicolumn{2}{|c|}{$v_{11}$ out-of-plane $\mathrm{H}$ bend } & \multicolumn{2}{|c|}{$v_{1} \mathrm{C}$ ring stretch (IR inactive in benzene) } & \multicolumn{2}{|c|}{$v_{18}$ in-plane $\mathrm{C}-\mathrm{H}$ bend } & \multicolumn{2}{|c|}{$v_{19}$ in-plane $\mathrm{C}$ ring distortion } \\
\hline & exptl & theory a & exptl & theory & exptl & theory ${ }^{a}$ & exptl & theory a \\
\hline $\mathrm{C}_{6} \mathrm{H}_{6}$ & 673 & $687(122)$ & 992 & $979 / 981(0)$ & 1038 & $1059 / 1059(6 / 6)$ & 1486 & $1510 / 1510(7 / 7)$ \\
\hline $\mathrm{Ti}^{+}(\mathrm{bz})$ & & $756(100)$ & & $899(4)$ & & $1003 / 1004(8 / 8)$ & & $1450 / 1450(11 / 11)$ \\
\hline $\mathrm{Ti}^{+}(\mathrm{bz})_{2}$ & 739 & $751(88)$ & 946 & $922 / 974(10 / 19)$ & $\begin{array}{l}992 \\
070^{b}\end{array}$ & $1011 / 1034(15 / 6)$ & 1421 & $1466 / 1478 / 1530(17 / 15 / 22)$ \\
\hline $\begin{array}{l}\mathrm{Ti}(\mathrm{bz})_{2} \\
\mathrm{~V}^{+}(\mathrm{bz})\end{array}$ & 769 & $744^{c}$ & $946^{b}$ & & $\begin{array}{l}979^{b} \\
980\end{array}$ & $1000 / 1016^{c}$ & 1425 & $1447 / 1458^{c}$ \\
\hline & & $791(103)$ & & $986 / 1001(5 / 11)$ & & $1005(2)$ & & $1423 / 1455 / 1528(7 / 2 / 7)$ \\
\hline $\mathrm{V}^{+}(\mathrm{bz})_{2}$ & 769 & $\begin{array}{l}724^{c} \\
761(75)\end{array}$ & 962 & 947/993(21/13) & 1005 & $\begin{array}{l}1010 / 1023^{c} \\
998 / 1020(11 / 3)\end{array}$ & 1449 & $\begin{array}{l}1456 / 1465^{c} \\
1462 / 1535(16 / 58)\end{array}$ \\
\hline $\begin{array}{l}\mathrm{V}(\mathrm{bz})_{2} \\
\mathrm{Cr}(\mathrm{bz})_{2}\end{array}$ & $739^{b}$ & & $\begin{array}{l}959^{b} \\
971^{b}\end{array}$ & & $\begin{array}{l}985^{b} \\
999^{b}\end{array}$ & & $1416^{b}$ & \\
\hline $\begin{array}{l}\mathrm{Cr}(\mathrm{bz})_{2} \\
\mathrm{Fe}^{+}(\mathrm{bz})\end{array}$ & $794^{b}$ & $767(101)$ & $971^{b}$ & $926 / 931(2 / 2)$ & $999^{b}$ & $1004 / 1021(5 / 3)$ & $1426^{b}$ & $1458 / 1465(16 / 20)$ \\
\hline $\mathrm{Fe}^{+}(\mathrm{bz})_{2}$ & 768 & $777(99)$ & 996 & $955(7)$ & & $1005 / 1031(4 / 7)$ & 1440 & $1453 / 1472(31 / 26)$ \\
\hline $\mathrm{Co}^{+}(\mathrm{bz})$ & 740 & $786(105)$ & & 929/931(1/1) & & $1012 / 1012(5 / 5)$ & 1430 & $1456 / 1457(15 / 15)$ \\
\hline $\mathrm{Co}^{+}(\mathrm{bz})_{2}$ & 748 & $737(160)$ & & $927(2)$ & & $1023 / 1023(5 / 5)$ & 1472 & $1469 / 1469(28 / 27)$ \\
\hline $\mathrm{Ni}^{+}(\mathrm{bz})$ & 744 & $764(105)$ & & & & $1005 / 1021(4 / 3)$ & 1444 & $1454 / 1464(19 / 18)$ \\
\hline $\mathrm{Ni}^{+}(\mathrm{bz})_{2}$ & 732 & $733(205)$ & & $1006(1)$ & & $1021 / 1032(5 / 5)$ & 1469 & $1469 / 1477(36 / 36)$ \\
\hline
\end{tabular}

${ }^{a}$ This work, except as noted. ${ }^{b}$ Literature values from the condensed phase, refs $9-11 .{ }^{c}$ Reference 12.

FELIX laser pulse, which has a series of picosecond micropulses within the 5-7 $\mu$ s macropulse. The photodissociation of the other metal ion complexes is conducted in a way similar to the vanadium experiments. On the basis of their known or calculated dissociation energies, all of these complexes are expected to require multiple-photon dissociation.

As we have described previously for $\mathrm{V}^{+}\left(\mathrm{C}_{6} \mathrm{H}_{6}\right), \mathrm{V}^{+}\left(\mathrm{C}_{6} \mathrm{H}_{6}\right)_{2}$, and $\mathrm{Al}^{+}$(benzene), ${ }^{12,13}$ IR multiple-photon dissociation is significantly enhanced when the laser is tuned into vibrational resonances of these complexes. Tuning the laser while recording the corresponding fragment ion yield provides IR-REMPD vibrational spectra for these complexes that are believed to match well in band positions with the infrared absorption spectrum. Because of the multiple-photon process, resonances in the IR-REMPD spectrum may be shifted slightly to the red from the corresponding bands in the absorption spectrum, which unfortunately cannot be measured. The line widths in these spectra (about $30 \mathrm{~cm}^{-1}$ here) are usually greater than the laser line width $\left(5-7 \mathrm{~cm}^{-1}\right)$, again due to the dynamics of the multiple-photon excitation. ${ }^{41,43}$ Moreover, band intensities are affected by the dissociation yield, and these may not match exactly with the corresponding absorption band intensities. Despite these limitations, the IR-REMPD method does allow vibrational spectra to be measured and systematic trends in the resonances to be investigated.

Figure 2 shows the IR-REMPD spectra for the monobenzene complexes of vanadium, cobalt, and nickel cations. Although we were able to measure spectra for dibenzene complexes of other metals (see below), these are the only monobenzene complexes that were produced with high enough intensity for these studies. As indicated, all three complexes have resonant bands in their photodissociation spectra in the region of 600$1700 \mathrm{~cm}^{-1}$. We also indicate in the figure three dashed vertical lines at 673,1038 , and $1486 \mathrm{~cm}^{-1}$. These mark the positions of the main IR-active vibrational bands of the gas-phase benzene molecule. ${ }^{36}$ They are respectively the $v_{11}$ (out-of-plane $\mathrm{C}-\mathrm{H}$ bend), $v_{18}$ (in-plane $\mathrm{C}-\mathrm{H}$ bend), and $v_{19}$ (in-plane carbon ring distortion) vibrational modes. It is apparent that strong resonances in the IR-REMPD spectra occur for all three complexes near the $v_{11}$ and $v_{19}$ bands in benzene, and a weaker band in the vanadium complex occurs near the $v_{18}$ band in benzene. The band positions in the IR-REMPD spectra are given in Table 1.

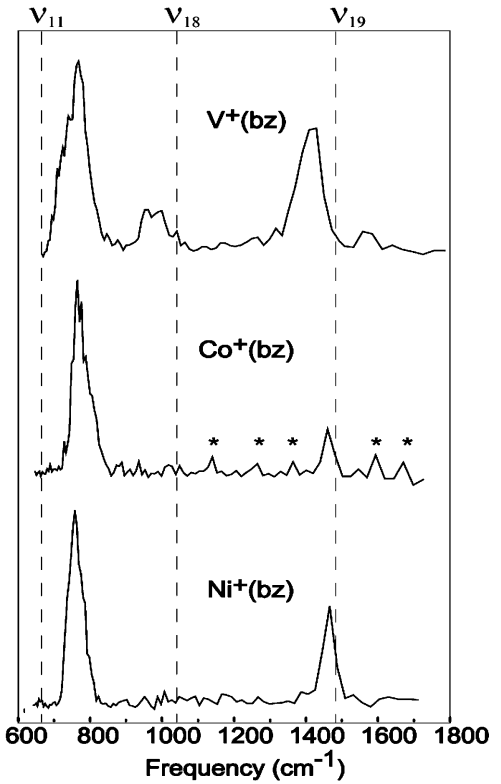

Figure 2. IR-REMPD vibrational spectra of $\mathrm{V}^{+}(\mathrm{bz}), \mathrm{Co}^{+}(\mathrm{bz})$, and $\mathrm{Ni}^{+}$(bz) measured in the $\mathrm{M}^{+}$fragment ion channel. Experiments such as those in Figure 1 were conducted to show that the $\mathrm{M}^{+}$fragment ion in each system comes from the corresponding $\mathrm{M}^{+}(\mathrm{bz})$ parent. The small peaks indicated with $*$ in the $\mathrm{Co}^{+}(\mathrm{bz})$ spectrum are noise peaks that are not reproducible.

Figures 3 and 4 show similar IR-REMPD vibrational spectra for the dibenzene complexes of titanium, vanadium, iron, cobalt, and nickel in the same infrared wavelength region. The positions of the vibrations in the free benzene molecule are again shown with vertical dashed lines. These spectra are qualitatively similar to the monobenzene complexes, with strong resonances seen near the $v_{11}$ and $v_{19}$ vibrations for all five metal complexes. The titanium and vanadium complexes have additional structure near the $v_{18}$ band, but this region of the spectrum has little or no intensity for the iron, cobalt, and nickel complexes. The band positions for these spectra are also given in Table 1.

It is evident from Figures 2-4 that all of these complexes have vibrational bands near those of the free benzene molecule. The bands in the $730-770 \mathrm{~cm}^{-1}$ region all occur at higher frequency than the $v_{11}\left(\mathrm{a}_{2 \mathrm{u}}\right)$ out-of-plane $\mathrm{C}-\mathrm{H}$ bending mode in benzene, which lies at $673 \mathrm{~cm}^{-1}$. The bands in the 900$1000 \mathrm{~cm}^{-1}$ region are not seen for all complexes, but they 


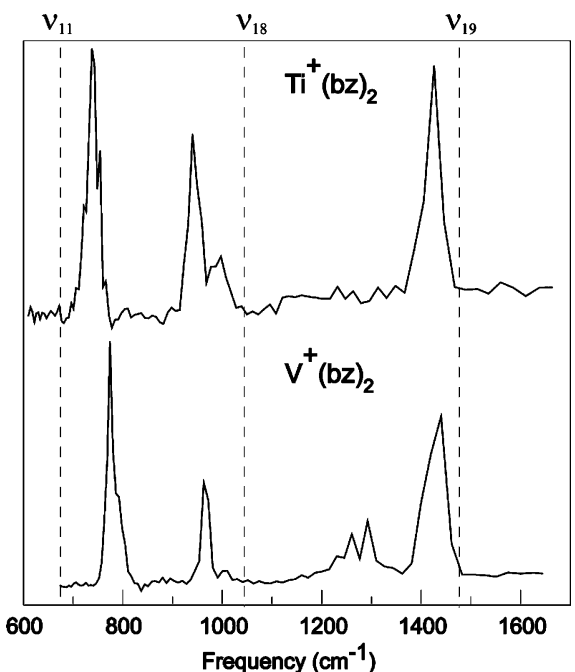

Figure 3. IR-REMPD vibrational spectra of $\mathrm{Ti}^{+}(\mathrm{bz})_{2}$ and $\mathrm{V}^{+}(\mathrm{bz})_{2}$ measured in the $\mathrm{M}^{+}(\mathrm{bz})$ fragment ion channel. Experiments such as those in Figure 1 were conducted to show that the $\mathrm{M}^{+}(\mathrm{bz})$ fragment ion in each system comes from the corresponding $\mathrm{M}^{+}(\mathrm{bz})_{2}$ parent.

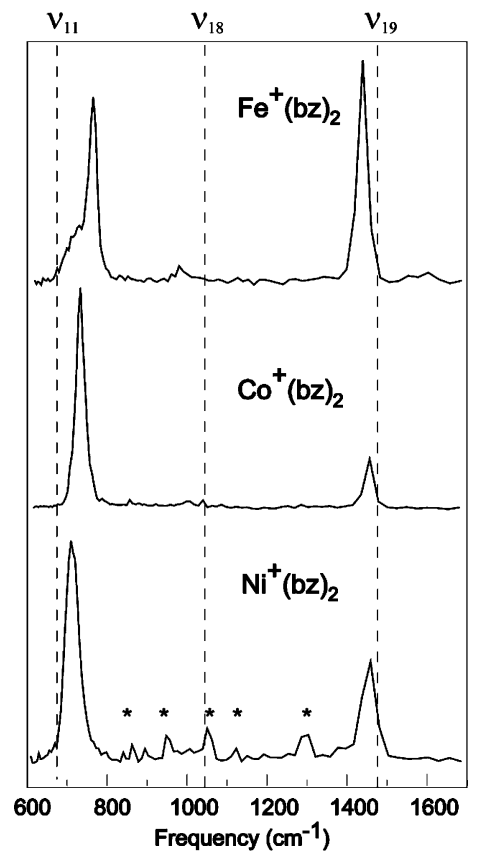

Figure 4. IR-REMPD vibrational spectra of $\mathrm{Fe}^{+}(\mathrm{bz})_{2}, \mathrm{Co}^{+}(\mathrm{bz})_{2}$, and $\mathrm{Ni}^{+}-$ $(\mathrm{bz})_{2}$ measured in the $\mathrm{M}^{+}(\mathrm{bz})$ fragment ion channel. Experiments such as those in Figure 1 were conducted to show that the $\mathrm{M}^{+}(\mathrm{bz})$ fragment ion in each system comes from the corresponding $\mathrm{M}^{+}(\mathrm{bz})_{2}$ parent. The small peaks indicated with $*$ in the $\mathrm{Ni}^{+}(\mathrm{bz})$ spectrum are noise peaks that are not reproducible.

generally appear at frequencies lower than those of the $v_{18}\left(\mathrm{e}_{1 \mathrm{u}}\right)$ in-plane $\mathrm{C}-\mathrm{H}$ bending mode, which occurs at $1038 \mathrm{~cm}^{-1}$. Strong bands are also seen in the $1420-1470 \mathrm{~cm}^{-1}$ region, and these generally lie at lower frequency than the $v_{19}\left(\mathrm{e}_{1 \mathrm{u}}\right)$ carbon ring deformation mode that occurs at $1486 \mathrm{~cm}^{-1}$ in benzene. Vibrational patterns similar to these have been seen and discussed previously for a variety of condensed-phase metal dibenzene complexes produced by conventional synthetic chemistry. ${ }^{9-11}$ These systems are usually studied in solution or in thin solid films, and therefore vibration band positions are not generally known for the isolated molecules. However, the vibrational assignments and their trends provide a convenient guide for our work. For comparison to our cation work, we include the band position of the previously studied neutral $\mathrm{V}(\mathrm{bz})_{2}$ and $\mathrm{Ti}(\mathrm{bz})_{2}$ complexes $^{9-11}$ in the table. Even though we were unable to obtain spectra for $\mathrm{Cr}^{+}(\mathrm{bz})_{1,2}$ complexes, we also include the known vibrations for neutral $\mathrm{Cr}(\mathrm{bz})_{2} \cdot{ }^{9-11}$

In the IR spectra of condensed-phase metal-benzene complexes, the $v_{11}$ and $v_{19}$ bands are the most prominent peaks. The $v_{11}$ band is usually shifted to the blue compared to the free benzene molecule, while the $\nu_{18}$ and $\nu_{19}$ bands are also shifted to the red. These trends have been discussed previously. ${ }^{9,10}$ When a transition metal binds to benzene, there is $\sigma$-donation of electron density from the molecular $\pi$-cloud to empty orbitals on the metal, and also $\pi$-back-bonding from the populated metal orbitals into the antibonding molecular orbitals. These effects, which are analogous to those seen for metal carbonyls and metal-olefin complexes, constitute the well-known DewarChatt-Duncanson model of $\pi$-bonding. ${ }^{44-46}$ The net result of these charge-transfer processes is that the molecular bonding in the benzene is weakened, which drives many of its vibrational frequencies to lower values. This explains the red shifts seen for the $v_{18}$ and $v_{19}$ vibrational bands. The exception to this trend occurs for the $v_{11}$ bands, which shift to higher frequencies. While the red shift is a chemical bonding/charge-transfer effect, the blue shift of the $v_{11}$ mode is more of a mechanical effect. The presence of the metal atom over the benzene ring provides an impediment to the out-of-plane hydrogen bend. The extra repulsion at the outer turning point of this vibration produces a steeper potential in this region, which drives the frequency higher. These trends have been seen previously in the condensedphase neutral dibenzene complexes that could be made and studied. ${ }^{9-11}$ We see the same effect here in cations of monobenzene complexes, which could not be studied before as neutrals, and for dibenzene cations of a wider variety of transition metals.

Another aspect of the previous IR spectroscopy on condensedphase complexes is that vibrational modes that are forbidden for benzene itself may become IR-active in the reduced symmetry of the metal complexes. For example, the $v_{1}\left(\mathrm{a}_{1 \mathrm{~g}}\right)$ vibration (symmetric ring stretch, $992 \mathrm{~cm}^{-1}$ ) is only Ramanactive in isolated benzene, but this mode is IR-active in many dibenzene complexes. ${ }^{9-11}$ The assignment of vibrational structure near $1000 \mathrm{~cm}^{-1}$ may involve this vibrational mode in addition to the expected $v_{18}$ mode.

To investigate these IR spectra in more detail and to elucidate the trends in vibrational band shifts, we performed DFT calculations on these complexes. The binding of benzene to cationic transition metals has been the subject of a variety of theoretical studies in the past. $^{21-28}$ The pioneering work of Bauschlicher and co-workers examined the monomer binding with the modified coupled pair functional formalism. ${ }^{22}$ The study of ref $24 \mathrm{~b}$ provided the first wide-ranging density functional study of the monomer binding. The B3LYP results were in good agreement with the MCPF results, thereby validating the use of this method for the present study of the dimer complexes. A related comparison of $\mathrm{CCSD}(\mathrm{T})$ and $\mathrm{B} 3 \mathrm{LYP}$ estimates for the binding of the cationic transition metals to acetylene and ethylene further validates the B3LYP density functional for the study of cationic transition-metal ligand binding. ${ }^{24 a}$

(44) Chatt, J.; Rowe, G. A.; Williams, A. A. Proc. Chem. Soc. 1957, 208-208. (45) Chatt, J.; Duncanson, L. A.; Guy, R. G. J. Chem. Soc. 1961, 827-834.

(46) Chatt, J.; Duncanson, L. A.; Guy, R. G.; Thompson, D. T. J. Chem. Soc. 1963, 5170-5183. 
Table 2. B3LYP/6-311++G(d,p)-Predicted Metal Ligand Binding Energies (kcal/mol) and Bond Lengths $(\AA)$ for Cation Metal Benzene (bz) Monomer and Dimer Complexes

\begin{tabular}{|c|c|c|c|c|c|c|c|}
\hline species & state $^{a}$ & sym & $\mathrm{D}_{0}$ (theory $^{b}$ & $D_{0}$ (exptl) & $R_{\mathrm{MX} 1^{c}}$ & $R_{\mathrm{MX} 2}{ }^{d}$ & $\theta_{\mathrm{XMX}}{ }^{e}$ \\
\hline $\operatorname{Ti}(\mathrm{bz})^{+}$ & ${ }^{4} A_{1}\left(3 d e_{2}^{2} 3 d_{1}\right)$ & $C_{6 v}$ & 54.5 & & 1.886 & & \\
\hline $\operatorname{Ti}(\mathrm{bz})_{2}{ }^{+}$ & ${ }^{4} \mathrm{~A}_{1}\left(3 \mathrm{de}_{2}^{2} 3 \mathrm{da}_{1}\right)$ & $D_{6}$ & 47.4 & & 1.984 & & \\
\hline $\mathrm{Ti}(\mathrm{bz})_{2}{ }^{+}$ & ${ }^{2} \mathrm{~A}_{\mathrm{g}}\left(3 \mathrm{de}_{2}^{3}\right)$ & $D_{2 h}$ & 48.3 & $51.0-60.4^{f}$ & 1.938 & & \\
\hline $\operatorname{Ti}(\mathrm{bz})_{2}{ }^{+}$ & ${ }^{2} B_{3 g}\left(3 d e_{2}^{2} 3 d a_{1}\right)$ & $D_{2 h}$ & 53.5 & & 1.872 & & \\
\hline $\mathrm{V}(\mathrm{bz})^{+}$ & ${ }^{5} \mathrm{~B}_{1}\left(3 \mathrm{de}_{2}^{2} 3 \mathrm{da}_{1} 3 \mathrm{de}_{1}\right)$ & $C_{2 v}$ & 47.5 & & 1.959 & & \\
\hline $\mathrm{V}(\mathrm{bz})^{+}$ & ${ }^{3} \mathrm{~A}_{2}\left(3 \mathrm{de}_{2}{ }^{3} 3 \mathrm{da}_{1}\right)$ & $C_{2 v}$ & 48.4 & $49.6-58.8^{f}$ & 1.685 & & \\
\hline $\mathrm{V}(\mathrm{bz})_{2}{ }^{+}$ & ${ }^{5}\left(3 \mathrm{de}_{2}^{2} 3 \mathrm{da}_{1} 3 \mathrm{de}_{1}\right)$ & $C_{1}$ & 32.2 & & 2.039 & 2.181 & 168.5 \\
\hline $\mathrm{V}(\mathrm{bz})_{2}{ }^{+}$ & ${ }^{3} B_{3 g}\left(3 d e_{2}{ }^{3} 3 d a_{1}\right)$ & $D_{2 h}$ & 55.7 & & 1.801 & & \\
\hline $\mathrm{Cr}(\mathrm{bz})^{+}$ & ${ }^{6} \mathrm{~A}_{1}\left(3 \mathrm{de}_{2}^{2} 3 \mathrm{da}_{1} 3 \mathrm{de}_{1}{ }^{2}\right)$ & $C_{6 v}$ & 36.4 & & 2.114 & & \\
\hline & & & & $47.0-55.3^{f}$ & & & \\
\hline $\mathrm{Cr}(\mathrm{bz})_{2}{ }^{+}$ & ${ }^{2} \mathrm{~A}_{1 \mathrm{~g}}\left(3 \mathrm{de}_{2}{ }^{4} 3 \mathrm{da}_{1}\right)$ & $D_{6 h}$ & 36.8 & $57.9^{g}$ & 1.662 & & \\
\hline $\mathrm{Mn}(\mathrm{bz})^{+}$ & ${ }^{7} A_{1}\left(3 d_{2}^{2} 3 d_{1} 3 d_{1}{ }_{1}^{2} 4 s^{1}\right)$ & $C_{6 v}$ & 31.5 & & 2.379 & & \\
\hline $\mathrm{Mn}(\mathrm{bz})^{+}$ & ${ }^{5} \mathrm{~A}_{1}\left(3 \mathrm{de}_{2}{ }^{3} 3 \mathrm{da}_{1} 3 \mathrm{de}_{1}^{2}\right)$ & $C_{2 v}$ & 27.8 & & 1.816 & & \\
\hline $\mathrm{Mn}(\mathrm{bz})_{2}{ }^{+}$ & ${ }^{1} A_{1}\left(3 d_{2}{ }^{4} 3 d a_{1}^{2}\right)$ & $D_{6 h}$ & 29.9 & $40.6-48.4^{f}$ & 1.631 & & \\
\hline $\mathrm{Fe}(\mathrm{bz})^{+}$ & ${ }^{6} \mathrm{~A}_{2}\left(3 \mathrm{de}_{2}{ }^{3} 3 \mathrm{da}_{1} 3 \mathrm{de}_{1}^{2} 4 \mathrm{~s}^{1}\right)$ & $C_{2 v}$ & 38.9 & & 2.218 & & \\
\hline $\mathrm{Fe}(\mathrm{bz})^{+}$ & ${ }^{4} \mathrm{~A}_{1}\left(3 \mathrm{de}_{2}{ }^{3} 3 \mathrm{da}_{1}{ }^{2} 3 \mathrm{de}_{1}^{2}\right)$ & $C_{2 v}$ & 49.0 & & 1.810 & & \\
\hline $\mathrm{Fe}(\mathrm{bz})_{2}{ }^{+}$ & ${ }^{4} \mathrm{~A}_{1 \mathrm{~g}}\left(3 \mathrm{de}_{2}{ }^{4} 3 \mathrm{da}_{1} 3 \mathrm{de}_{1}{ }^{2}\right)$ & $D_{6 h}$ & 32.5 & & 1.865 & & \\
\hline $\mathrm{Fe}(\mathrm{bz})_{2}{ }^{+}$ & ${ }^{4} \mathrm{~A}\left(3 \mathrm{de}_{2}^{3} 3 \mathrm{da}_{1}^{2} 3 \mathrm{de}_{1}^{2}\right)$ & $C_{2}$ & 36.2 & & 2.040 & & \\
\hline $\mathrm{Fe}(\mathrm{bz})_{2}{ }^{+}$ & ${ }^{2} \mathrm{~B}_{1 \mathrm{~g}}\left(3 \mathrm{de}_{2}^{4} 3 \mathrm{da}_{1}^{2} 3 \mathrm{de}_{1}\right)$ & $D_{2 h}$ & 40.6 & $37.8-44.7^{f}$ & 1.714 & & \\
\hline $\mathrm{Co}(\mathrm{bz})^{+}$ & ${ }^{3} \mathrm{~A}_{2}\left(3 \mathrm{de}_{2}{ }^{4} 3 \mathrm{da}_{1}{ }^{2} 3 \mathrm{de}_{1}^{2}\right)$ & $C_{2 v}$ & 58.6 & & 1.672 & & \\
\hline $\mathrm{Co}(\mathrm{bz})_{2}{ }^{+}$ & ${ }^{3} \mathrm{~A}_{1}\left(3 \mathrm{de}_{2}{ }^{4} 3 \mathrm{da}_{1}{ }^{2} 3 \mathrm{de}_{1}^{2}\right)$ & $D_{6}$ & 35.9 & $34.6-39.9^{f}$ & 1.857 & & \\
\hline $\mathrm{Ni}(\mathrm{bz})^{+}$ & ${ }^{2} \mathrm{~B}_{2}\left(3 \mathrm{de}_{2}{ }^{4} 3 \mathrm{da}_{1}{ }^{2} 3 \mathrm{de}_{1}{ }^{3}\right)$ & $C_{2 v}$ & 57.4 & & 1.738 & & \\
\hline $\mathrm{Ni}(\mathrm{bz})_{2}{ }^{+}$ & ${ }^{2}\left(3 \mathrm{de}_{2}^{4} 3 \mathrm{da}_{1}^{2} 3 \mathrm{de}_{1}^{3}\right)$ & $C_{1}$ & 33.7 & $30.7-35.1^{f}$ & 1.971 & & \\
\hline $\mathrm{Cu}(\mathrm{bz})^{+}$ & ${ }^{2} \mathrm{~A}_{1}\left(3 \mathrm{de}_{2}{ }^{4} 3 \mathrm{da}_{1}^{2} 3 \mathrm{de}_{1}^{4}\right)$ & $C_{6 v}$ & 49.1 & & 1.859 & & \\
\hline $\mathrm{Cu}(\mathrm{bz})_{2}{ }^{+}$ & ${ }^{2} \mathrm{~A}_{1}\left(3 \mathrm{de}_{2}{ }^{4} 3 \mathrm{da}_{1}^{2} 3 \mathrm{de}_{1}^{4}\right)$ & $C_{1}$ & 35.2 & $32.1-37.1^{f}$ & 2.434 & 2.407 & 146.7 \\
\hline
\end{tabular}

a The orbital prescription in parentheses corresponds to the occupation of the metal $3 \mathrm{~d}$ and $4 \mathrm{~s}$ orbitals using a notation corresponding to that of the metal orbitals in $C_{6 v}$ symmetry. ${ }^{b} \mathrm{~B} 3 \mathrm{LYP} / 6-311++\mathrm{G}^{* *}$ predicted dissociation energy for the process $\mathrm{M}^{+}(\mathrm{bz})_{n} \rightarrow \mathrm{M}+(\mathrm{bz})_{n-1}$ in kilocalories per mole including zero-point correction. ${ }^{c}$ Distance from metal cation to center of C6 ring. For asymmetric dimers, this corresponds to the value for one of the rings. ${ }^{d}$ Distance from metal cation to center of second C6 ring for asymmetric dimers. ${ }^{e}$ Angle in degrees from the center of one C6 ring to the metal to the center of the other C6 ring. For the symmetric dimers, this value is $180 .{ }^{f}$ Dissociation energy obtained from modeling of collision-induced dissociation measurements of ref $18 \mathrm{~b}$. The first number corresponds to that obtained from a tight RRKM modeling, while the second number corresponds to that obtained from a loose RRKM modeling. ${ }^{g}$ Dissociation energy obtained from modeling of photoelectron-photoion coincidence experiments of ref 27.

Rao and co-workers have provided a fairly complete analysis of the dimer binding employing the BPW91 density functional. ${ }^{26}$ The present study, which employs the B3LYP rather than BPW91 functional, provides a more detailed description of the electronic states involved, allows for symmetry breaking from $D_{6 h}$ symmetry to obtain true minima, and obtains vibrational properties for each of the states considered. The present study is directly analogous to that of ref $24 \mathrm{~b}$ for the monomers, but employs a slightly larger basis set to obtain more well-converged estimates of the infrared spectral properties for comparison with the present experimental results. More limited DFT studies of the $\mathrm{V}^{+}, \mathrm{Cr}^{+}$, and $\mathrm{Fe}^{+}$benzene dimers have been provided by Bowers and co-workers, ${ }^{21}$ by $\mathrm{Li}$ and Baer, ${ }^{27}$ and by Kaczorowska and Harvey, ${ }^{28}$ respectively.

The present B3LYP/6-311++ $\mathrm{G}(d, p)$ calculations find stable minima for all the monomer and dimer metal-benzene cation complexes. The structures found and the low energy electronic states are indicated in Table 2. For the monomer complexes, the structures found are either the simple $C_{6 v}$ or the $C_{2 v}$ in which the benzene ring has two carbon atoms distorted toward the metal. $\mathrm{Ti}^{+}, \mathrm{Cr}^{+}, \mathrm{Mn}^{+}$, and $\mathrm{Cu}^{+}$complexes adopt the $C_{6 v}$ structure, while $\mathrm{V}^{+}, \mathrm{Mn}^{+}, \mathrm{Fe}^{+}, \mathrm{Co}^{+}$, and $\mathrm{Ni}^{+}$adopt the $C_{2 v}$. Only $\mathrm{Mn}^{+}$exhibits both structures in different spin states. There is a noticeable trend for the more strongly bound complexes (see below) to form the $C_{2 v}$ structure. The dimer complexes may also have undistorted $D_{6 h}$ and $D_{6 d}$ structures, depending on whether the benzene rings are eclipsed or staggered with respect to each other. For several complexes, there is a negligible energy difference between the staggered and eclipsed forms. However, as in the monomers, many of the more strongly bound dimer complexes have structures in which the benzene rings
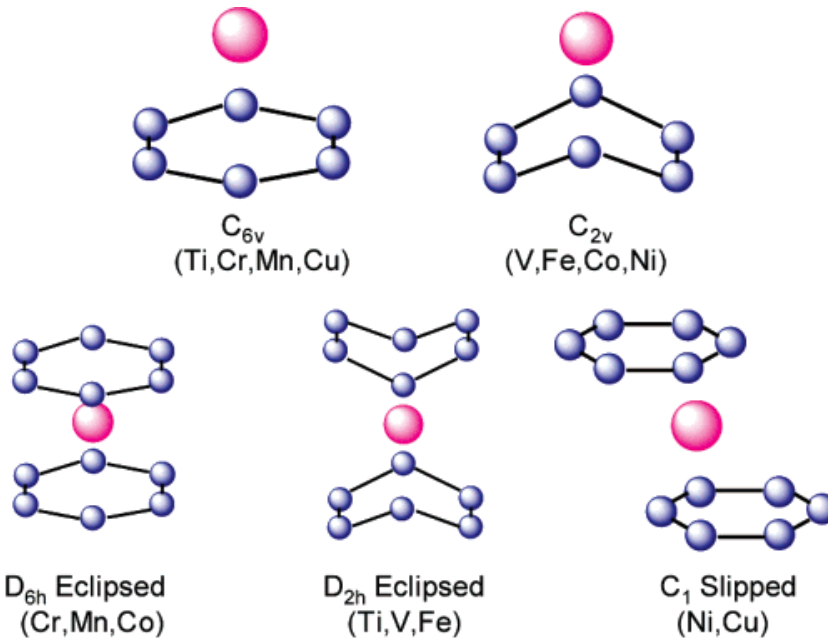

$(\mathrm{Ti}, \mathrm{V}, \mathrm{Fe})$

(Ni,Cu)

Figure 5. Schematic structures calculated for various metal dibenzene sandwich complexes. Hydrogens are removed, and ring distortions are exaggerated in these structures compared to the actual predictions of theory.

are distorted. For example, a $D_{2 h}$ structure occurs for several complexes that have two carbons in each benzene ring displaced toward the metal, analogous to the monomer $C_{2 v}$ structure. A $\mathrm{C}_{1}$ complex has the metal localized over an $\eta^{3}$ site on each benzene ring. Selected structures for some of these monomer and dimer complexes are shown in Figure 5.

The binding energies and metal-ligand bond lengths for the monomer and dimer cationic metal benzene complexes are presented in Table 2 and shown graphically in Figures 6 and 7, respectively. These values are compared to previous experimental results in Table 2. These results are based on the coupling of purely theoretical estimates for the spin-conserving dissocia- 


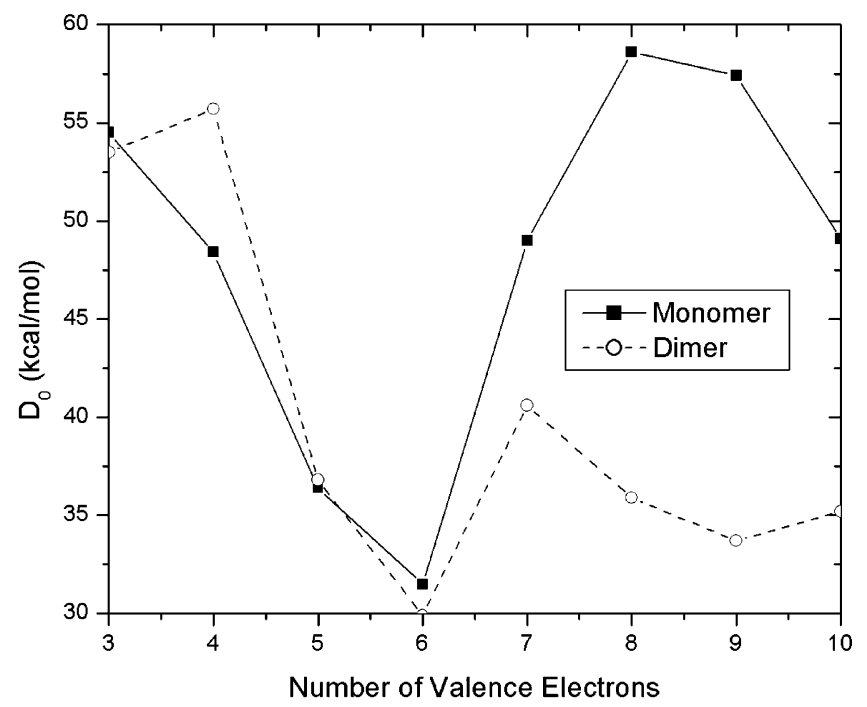

Figure 6. Plot of the calculated dissociation energy, $\mathrm{M}^{+}(\mathrm{bz})_{n} \rightarrow \mathrm{M}^{+}(\mathrm{bz})_{n-1}$, versus number of valence electrons for the monomer and dimer metal benzene cations.

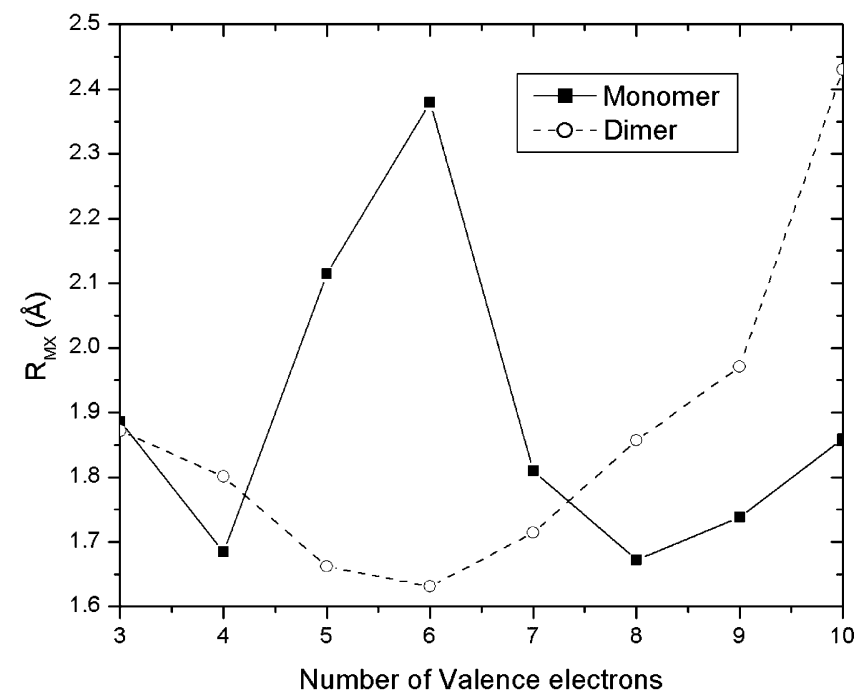

Figure 7. Plot of the calculated metal ligand bond length versus number of valence electrons for the monomer and dimer metal benzene cations.

tion process with experimental values for the spin excitation process in the metal cation. For the ${ }^{5} \mathrm{Mn}^{+}$configuration we could not obtain a ${ }^{5} \mathrm{~d}^{6}$ state in the metal ion, and for ${ }^{1} \mathrm{Mn}^{+}$an experimental value was not available. Thus, purely theoretical estimates were employed for these states.

The ground electronic state generally corresponds to a configuration in which the degenerate (in $C_{6 v}, D_{6 h}$, and $D_{6 d}$ symmetry) $3 \mathrm{de}_{2}$ orbitals are occupied first, followed by the $3 \mathrm{da}_{1}$ orbital, and finally the $3 \mathrm{de}_{1}$ orbitals, which are also degenerate in $C_{6 v}, D_{6 h}$, and $D_{6 d}$ symmetries. Only the quartet $\mathrm{Fe}^{+}$-benzene monomer and dimer complexes break this rule by doubly occupying the $3 \mathrm{da}_{1}$ orbital before adding the fourth electron to the $3 \mathrm{de}_{2}$ orbitals.

The results for the monomer complexes are very similar to those presented in an earlier study, ${ }^{24 \mathrm{~b}}$ but with slightly decreased binding energies, apparently due to the increased size of the basis set employed for the $\mathrm{C}$ and $\mathrm{H}$ atoms. This decrease in the predicted bond strength is fairly consistent, ranging from 2.2 to $3.0 \mathrm{kcal} / \mathrm{mol}$, with an average decrease of $2.5 \mathrm{kcal} / \mathrm{mol}$. A detailed comparison with experimental results was provided in the earlier work and thus is not included here. The present results also suggest that the ${ }^{3} \mathrm{~A}_{2}$ state in the $\mathrm{V}^{+}(\mathrm{bz})$ complex has a slightly greater binding energy than the ${ }^{5} \mathrm{~B}_{1}$ or ${ }^{5} \mathrm{~B}_{2}$ states. This is in contrast to the result presented in our previous communication on $\mathrm{V}^{+}$(benzene) (b,2 $_{\text {IR-REMPD spectroscopy. }}{ }^{12}$

The dimer complexes tend to have a low-spin ground state, while the monomer complexes tend to be high-spin. In particular, $\mathrm{Ti}^{+}(\mathrm{bz})_{2}$ is calculated to be a doublet, whereas $\mathrm{Ti}^{+}-$ (bz) is a quartet; $\mathrm{V}^{+}(\mathrm{bz})_{2}$ has a triplet binding energy that is 23 $\mathrm{kcal} / \mathrm{mol}$ greater than the quintet, whereas the monomer triplet and quintet are within $1 \mathrm{kcal} / \mathrm{mol}$ of each other; $\mathrm{Cr}^{+}(\mathrm{bz})_{2}$ is a doublet, whereas $\mathrm{Cr}^{+}(\mathrm{bz})$ is a sextet; $\mathrm{Mn}^{+}(\mathrm{bz})_{2}$ is a singlet, whereas $\mathrm{Mn}^{+}(\mathrm{bz})$ is a septet; and $\mathrm{Fe}^{+}(\mathrm{bz})_{2}$ is a doublet, whereas $\mathrm{Fe}^{+}(\mathrm{bz})$ is a quartet. The spin state for a given complex is the result of a balance between the promotion energy required to pair up the spins in the metal and the improved metal-ligand binding for paired spins. The enhanced binding for the two ligands of the dimer complexes more than compensates for the promotion energy, while the single ligand binding generally does not.

The bond strengths for the second ligand in the $\mathrm{Ti}^{+}, \mathrm{Cr}^{+}$, and $\mathrm{Mn}^{+}$dimer complexes are essentially identical to those for the corresponding monomer complexes, indicating a near equivalence of the promotion energy and the improved binding. For the $\mathrm{V}^{+}$complex, even the monomer complex appears to have a reduced spin configuration, and the dimer bond strength is significantly greater than the monomer value. For the later transition metals $\left(\mathrm{Fe}^{+}\right.$through $\left.\mathrm{Cu}^{+}\right)$, the filling of the d-shell adds significant repulsion, and the dimer complexes are much more weakly bound than the monomer species. For these later transition metals, the predicted first dissociation energy of the dimer complexes is in good agreement with those extracted from modeling of collision-induced dissociation experiments. ${ }^{18}$ In contrast, the first dissociation energies for $\mathrm{Cr}^{+}$and $\mathrm{Mn}^{+}$appear to be significantly underestimated, while those for $\mathrm{Ti}^{+}$and $\mathrm{V}^{+}$ are slightly below the lower of the experimental estimates. It is perhaps worth noting that the estimated kinetic shifts applied to the extraction of the binding energies from the CID experiments tend to be much greater for these early transition metals. For $\mathrm{Ti}^{+}$, which has the largest kinetic shift, it is $33 \mathrm{kcal} /$ mol for the tight RRKM modeling. For the dimer complexes, the increased ligand-ligand repulsion implies that the tight RRKM-based modeling is more likely valid than in the monomer cases. Thus, some of the discrepancies may just be due to the uncertainty in the RRKM modeling process. Alternatively, the discrepancies may be related to the apparently nonadiabatic nature of the dissociations for these earlier transition metals or to simple inaccuracies in the quantum chemical simulations. For $\mathrm{Mn}^{+}$, the error may also be related to the absence of an experimental spin correction for the singlet dissociation predictions.

The present predictions for the bond strengths differ greatly from those obtained by Rao and co-workers ${ }^{26}$ on the basis of the BPW91 density functional. For example, for the dimer complexes only the predictions for $\mathrm{Ni}^{+}$agree to within $10 \mathrm{kcal} /$ mol. The spin state for the dimer complexes is predicted to be the same in both studies. However, Rao and co-workers predict a quintet ground state for the Mn monomer system.

The present B3LYP-predicted metal ligand bond lengths generally decrease with decreasing spin. However, the decrease 
with spin competes with an increased repulsion and thus bond length for multiple ligands. Thus, for $\mathrm{Ti}^{+}$and $\mathrm{Fe}^{+}$, where the dimer complex spin is lower (quartet versus doublet), the monomer and dimer complex bond lengths are similar. For $\mathrm{V}^{+}$ and $\mathrm{Co}^{+}$, the spins are identical and the dimer system has a somewhat greater bond length. For $\mathrm{Cr}^{+}$and $\mathrm{Mn}^{+}$, the two dimer complexes have much smaller bond lengths because of the pairing of multiple sets of electrons. For $\mathrm{Ni}^{+}$and $\mathrm{Cu}^{+}$, the nearly complete filling of the d-shell leads to increased repulsions, and the dimer complexes have much greater bond lengths. Indeed, for the $\mathrm{Cu}^{+}$case, the repulsions lead to a significant distortion away from the $\mathrm{C}_{6}$ axis.

The present $\mathrm{B} 3 \mathrm{LYP} / 6-311++\mathrm{G}(d, p)$ predictions for the vibrational properties of these complexes are reported in Table 1. For brevity, only those modes with significant IR activity (i.e., predicted to have an intensity of greater than $1.0 \mathrm{~km} / \mathrm{mol}$ ) are provided. A complete listing of the vibrational and structural properties can be found in the Supporting Information. The entries in Table 1 have been scaled from those resulting directly from the DFT calculations. The unscaled values are listed in the Supporting Information. The scaling, which amounts to shifts of $10-20 \mathrm{~cm}^{-1}$, is applied on a per-mode basis, using the difference between the calculated and experimental values for each vibration when free benzene is calculated at this same level of theory. These IR intensities and vibrational frequencies are used below as an aid in the interpretation of the IR spectra.

The theoretically predicted vibrations are first useful in confirming our suspected vibrational assignments and in clarifying other questionable assignments. The bands measured in our spectrum near the positions of the benzene $v_{11}$ and $v_{19}$ bands are indeed found by theory to be the corresponding vibrations in all of the respective mono- and dibenzene complexes. As discussed above, theory confirms the general trend that the $v_{11}$ bands shift to higher frequencies in the metal complexes and that the $v_{19}$ bands shift to lower frequencies in the metal complexes compared to the frequencies of free benzene. However, the quantitative agreement between theory and experiment for the positions of vibrational bands is less satisfying. Although for some bands the agreement is close (10$\left.20 \mathrm{~cm}^{-1}\right)$, for others the differences are as great as $50-60 \mathrm{~cm}^{-1}$. The IR-REMPD bands can easily be red-shifted by $10 \mathrm{~cm}^{-1}$ or so from the absorption bands; consideration of this would reduce some of these discrepancies but would make others worse. Throughout these metal complexes, the $v_{11}$ vibrational band is predicted to have by far the highest IR oscillator strength of all the bands, consistent with the much higher measured intensity for this band in the infrared spectrum of benzene. For example, the calculated intensity of the $v_{11}$ band compared to that of the $v_{19}$ band ranges from a factor of about 2 in the early transition metals and becomes as much as about a factor of 5 in the later transition metals. However, these predicted IR intensity differences are not so obvious in the measured spectra, where the $v_{11} / \nu_{19}$ bands are often about the same size or within a factor of 2. Only in the $\mathrm{Co}^{+}(\mathrm{bz})_{1,2}$ complexes is there a measured intensity ratio for these bands that approaches the calculated values. As noted above, the intensities measured in IR-REMPD spectra depend on both the IR absorption strength and the dissociation yield in these clusters. Apparently, the relative intensities of the $v_{11}$ bands in IR-REMPD are sometimes depressed compared to the calculated absorption intensities. A

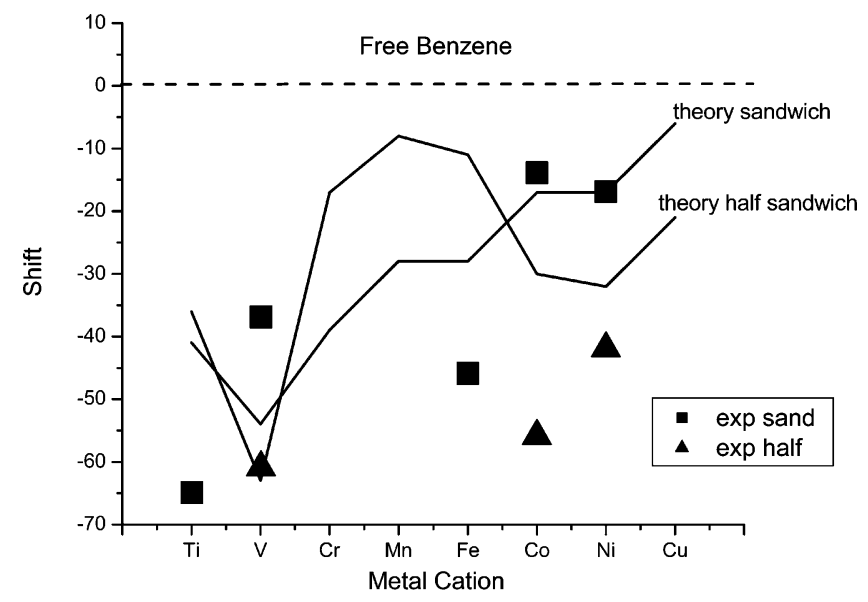

Figure 8. Shift of the $v_{19}$ vibrational mode relative to the energy of the free benzene mode for the different mono- and dibenzene complexes studied here. (ם) Measured shift for dibenzene complexes. ( $\boldsymbol{\Delta})$ Measured shift for monobenzene complexes. The lines indicate the predictions of theory.

lower dissociation yield here is not surprising because dissociation at the $v_{11}$ band requires more photons than dissociation at the $v_{19}$ band.

Theory can also help in the assignment of bands in the 1000 $\mathrm{cm}^{-1}$ region, where the IR-active $v_{18}$ band and the IR-forbidden $v_{1}$ band in free benzene occur. Doublet peaks are observed here for the $\mathrm{Ti}^{+}(\mathrm{bz})_{2}$ and $\mathrm{V}^{+}(\mathrm{bz})_{2}$ complexes, and a weak feature is also seen in the $\mathrm{Fe}^{+}(\mathrm{bz})_{2}$ spectrum. In the previous work in the condensed phase, ${ }^{9-11}$ both of these modes have been assigned in the IR spectra of metal complexes. As seen in Table 1, the lower frequency mode in the $1000 \mathrm{~cm}^{-1}$ region for the monomer and dimer complexes of $\mathrm{Ti}^{+}, \mathrm{V}^{+}$, and $\mathrm{Fe}^{+}$is indeed predicted to be the $v_{1}$ mode that is IR-forbidden for benzene. This mode is calculated to have a comparable or even greater intensity than the $v_{18}$ band that is IR-active in benzene.

Theory not only aids in the assignment of bands, but it also elucidates patterns in the vibrational band shifts. $v_{19}$ has been identified in the previous theoretical work of Chaquin and coworkers as a key indicator for the degree of metal-benzene charge-transfer interaction. ${ }^{25}$ In the present work, both the experiment and theory find substantial red shifts in the $v_{19}$ bands for all of these complexes. Figure 8 shows a comparison of the red shift of this mode measured for the different metal ion complexes versus the predictions of theory. As indicated, there is a general trend seen in the experiments and predicted by theory for the early transition-metal complexes to have a greater $v_{19}$ red shift than the later ones. In a general way, the shifts predicted seem to parallel the trend in bond energies. For example, relatively small shifts are predicted for $\mathrm{Mn}^{+}$and $\mathrm{Cr}^{+}$, consistent with their low calculated binding energies. Unfortunately, we are not able to obtain the experimental shifts for these metals. However, the correspondence with binding energy does not always hold up. A nice comparison is possible for $\mathrm{V}, \mathrm{Co}$, and $\mathrm{Ni}$, where we have data for both the mono- and dibenzene complexes. In the case of cobalt and nickel, the bond strengths calculated for the dibenzene complexes are less than those for the monomers, and the $v_{19}$ red shifts are also less for the dibenzene species. This trend is predicted by theory. However, for vanadium, the monomer has a weaker bond and yet a greater $v_{19}$ red shift. Again, this trend is predicted correctly by DFT. If it is correct to associate the $v_{19}$ shift with metal-ligand charge transfer, then charge transfer does not correlate directly to bond 


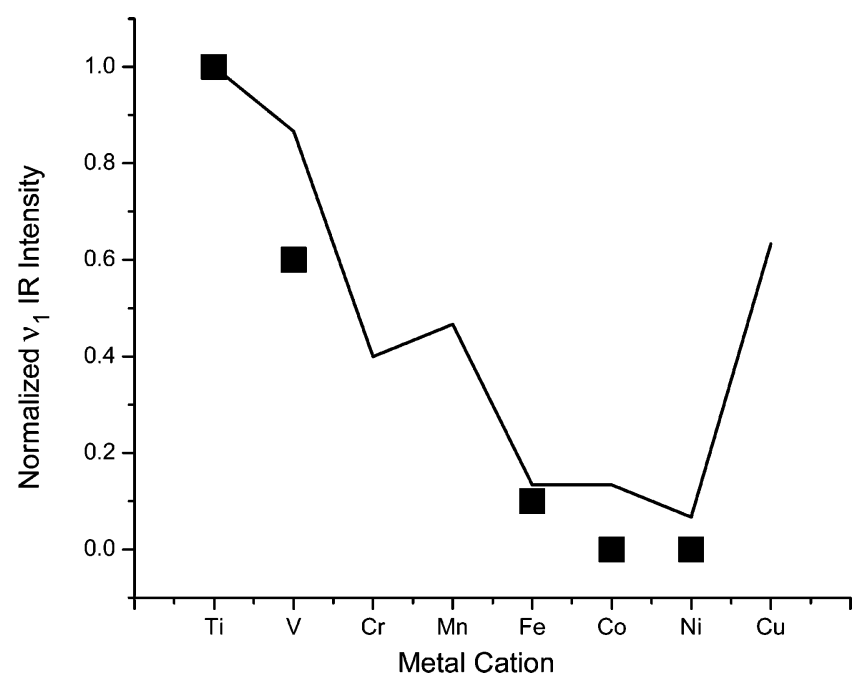

Figure 9. Measured relative intensity of the $v_{1}$ vibrational band ( $\square$ compared to the predictions of theory (line) for the various dibenzene complexes.

strength. However, it is reasonable that the amount of charge transfer would be greater for the early transition metals that have the greater $v_{19}$ red shifts. These metals have fewer d-electrons available for $\pi$-back-bonding, and thus $\sigma$-donation of charge toward the metal should be the dominant bonding interaction.

Another trend apparent in both the theory and the experimental vibrational spectra is the relative intensity of the $v_{1}$ vibrational bands. As noted above, this band is prominent in the spectra of $\mathrm{Ti}^{+}(\mathrm{bz})_{2}$ and $\mathrm{V}^{+}(\mathrm{bz})_{2}$ complexes, but is hardly detected in any other systems except $\mathrm{Fe}^{+}(\mathrm{bz})_{2}$. Figure 9 shows a comparison of the intensities measured for this band in the dibenzene complexes to those predicted with DFT. Our IRREMPD spectra do not measure IR absorption strengths directly, and therefore, to obtain this comparison we have arbitrarily set the measured intensity of this band in the $\mathrm{Ti}^{+}(\mathrm{bz})_{2}$ spectrum to be equal to its calculated IR intensity. It is then evident that the relative trend predicted and measured is for a greater $v_{1}$ intensity for the early transition metals. We have incomplete data for the monobenzene complexes, but consistent with this trend, the $\mathrm{V}^{+}(\mathrm{bz})$ spectrum does have a measurable $\nu_{1}$ band while the corresponding $\mathrm{Co}^{+}$and $\mathrm{Ni}^{+}$complexes do not. This is interesting because the monomer complexes of $\mathrm{Co}^{+}$and $\mathrm{Ni}^{+}$are more strongly bound than the $\mathrm{V}^{+}$species. The $v_{1}$ band intensity is apparently also not correlated directly with bond strength. However, it appears to be correlated with the extent of charge transfer. In every case, a higher intensity for the $v_{1}$ band parallels a strong $\nu_{19}$ red shift. Both effects are greatest in the early transition metals. It is important to note that these complexes with IR intensity in the $v_{1}$ band all have distorted benzene, i.e., $C_{2 v}$ structures for the monomers and $D_{2 h}$ structures for the dimers. Indeed, it is this distortion that induces the IR activity in this mode. The presence of a $v_{1}$ vibration could therefore be a diagnostic for distorted benzene.

As noted above, the metal spin state is a significant issue in the electronic structure of these complexes. We therefore wish to compare the vibrational spectra predicted for different spin configurations to the measured spectra to see if the IR data provide any insight. $\mathrm{Ti}^{+}(\mathrm{bz})_{2}$ provides an interesting test for this, because the ${ }^{4} \mathrm{~A}_{1}$ and ${ }^{2} \mathrm{~B}_{3 \mathrm{~g}}$ configurations are found to lie

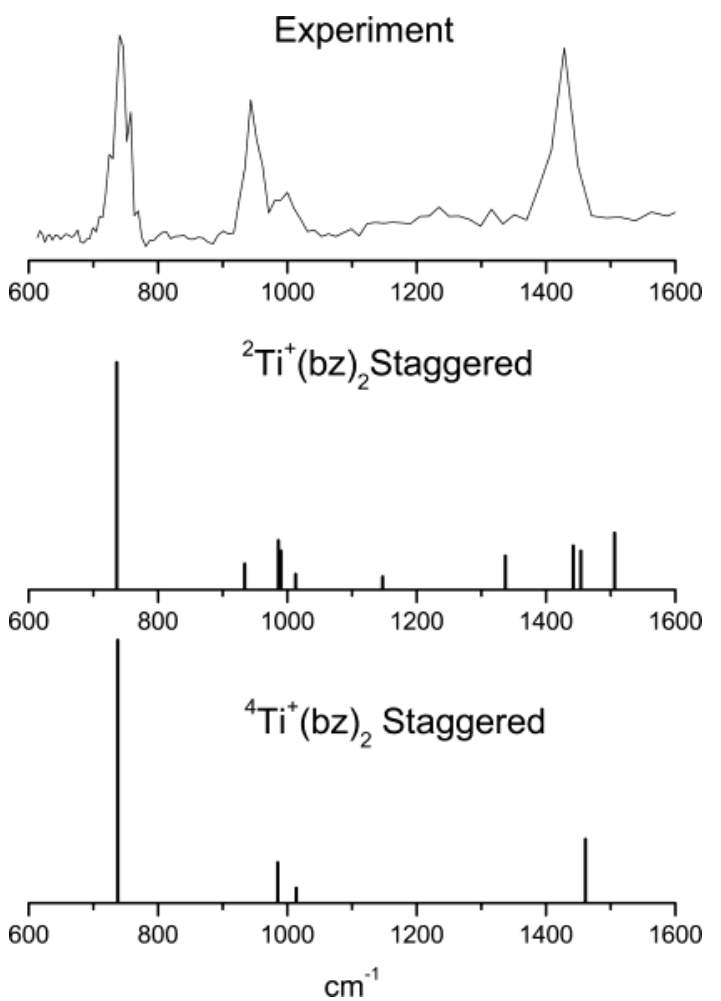

Figure 10. Comparison of the vibrational spectrum measured for $\mathrm{Ti}^{+}$(benzene $)_{2}$ with that calculated for the quartet versus doublet spin for the ground state.

energetically within about $6 \mathrm{kcal} / \mathrm{mol}$ of each other. Figure 10 shows the vibrational spectrum measured for $\mathrm{Ti}^{+}(\mathrm{bz})_{2}$ together with stick spectra predicted for the two spin configurations. It is evident that the doublet species has strong vibrational bands predicted near 1330 and $1510 \mathrm{~cm}^{-1}$, where no bands are detected experimentally. On the other hand, the quartet has a much simpler predicted spectrum, with bands nicely matching the experiment. In this case, the IR spectrum favors the quartet spin configuration, even though theory finds that the doublet is more stable. A similar discrepancy was discussed in our earlier work on $\mathrm{V}^{+}(\mathrm{bz})_{2}{ }^{12}$ Our newer calculations here agree with those done before, indicating that the triplet state is more stable than the quintet by about $25 \mathrm{kcal} / \mathrm{mol}$. However, as we discussed in the earlier communication, ${ }^{12}$ the vibrational spectrum that we measured matches the quintet significantly better than it does the triplet. Perhaps the simplest explanation to consider for both of these discrepancies is that the energetics of different spin states are not handled correctly by DFT. In fact, it is well-known that DFT has difficulties with the energetics of open shell species. ${ }^{47}$ The energy difference between quintet and triplet states for $\mathrm{V}^{+}(\mathrm{bz})_{2}$ is substantial, but the energy difference of 6 $\mathrm{kcal} / \mathrm{mol}$ between the two spin states for $\mathrm{Ti}^{+}(\mathrm{bz})_{2}$ is much smaller, perhaps making such a mistake understandable for the latter system. On the other hand, as we discussed previously, ${ }^{12}$ it is conceivable that the ion production method used here (photoionization) preferentially produces the ions in metastable excited states that do not relax within the time between the ionization laser and the probe IR pulse. In the present configuration of the experiment, it is not possible to introduce collisions that might relax excited states if they are formed. In

(47) Cramer, C. J. Essentials of Computational Chemistry, Wiley: West Sussex, U.K., 2002. 


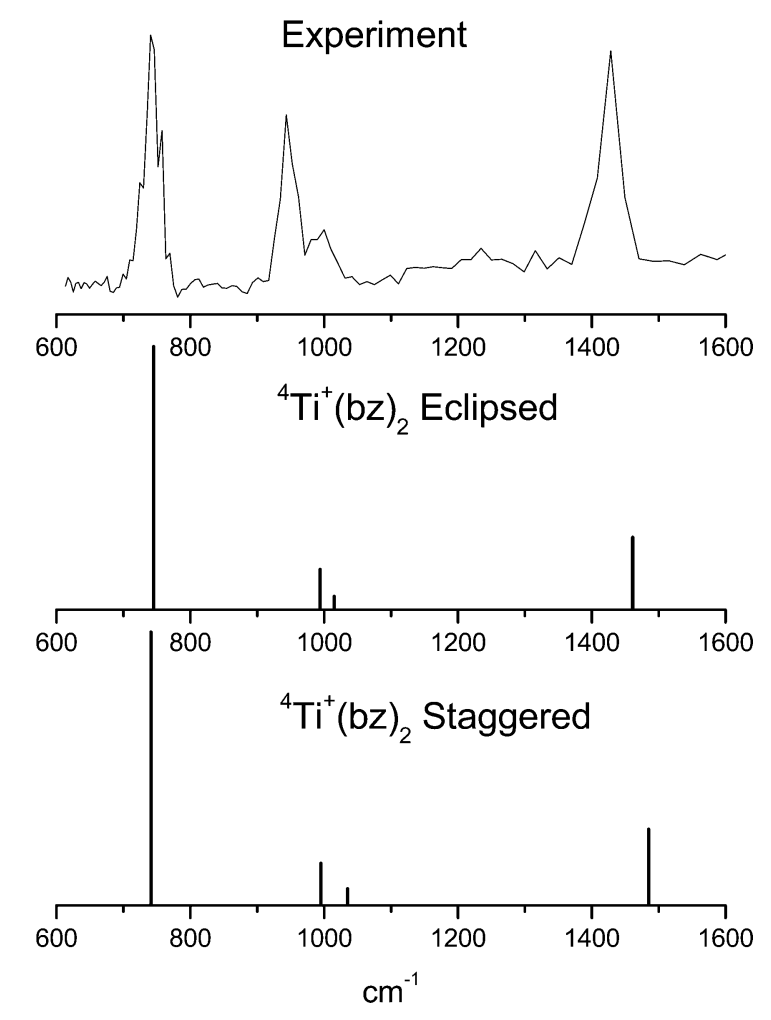

Figure 11. Comparison of the vibrational spectrum measured for $\mathrm{Ti}^{+}-$ (benzene $)_{2}$ with that predicted for the eclipsed versus staggered isomers for the quartet ground state.

the future, it will be important to make the ions in different ways to try to ensure that the lowest configuration is indeed produced. We have already done this for the $\mathrm{V}^{+}(\mathrm{bz})_{2}$ complex using a different molecular beam machine, where the ions were produced directly in a laser plasma and then cooled by supersonic expansion. ${ }^{48}$ Studies of the $\mathrm{C}-\mathrm{H}$ stretch vibrations in this experiment were also more consistent with the assignment of the ground state of this ion as a quintet, again calling into question the capability of DFT for this spin state problem. Other metal complexes studied here are also predicted to have closely lying spin configurations. However, we were not able to obtain spectra for all of these. Of the complexes for which we have spectra, the $\mathrm{V}^{+}(\mathrm{bz})$ monomer and the $\mathrm{Fe}^{+}(\mathrm{bz})_{2}$ dimer are the only other species that have two closely spaced states with different multiplicities. However, the vibrational patterns calculated for these complexes are very similar in both spin states, precluding any critical comparison with the measured spectra.

Another more subtle effect in the spectroscopy of these complexes is the possibility of detecting the conformation of the two rings in a dibenzene complex. The issue of staggered versus eclipsed rings has been pervasive in the historical discussion of metal-dibenzene complexes. ${ }^{8-11}$ It is therefore interesting to see if the comparison between theory and experiment can provide any insight into this issue. Figure 11 shows the experimental spectrum of $\mathrm{Ti}^{+}(\mathrm{bz})_{2}$ together with the stick spectra predicted for both the eclipsed and staggered conformations. As indicated in the figure, the only spectroscopic difference predicted by DFT for these two conformations is the splitting between the $v_{1}$ and $v_{18}$ bands. The staggered conformation, which is calculated to be more stable, is predicted to have

(48) Jaeger, T. D.; Duncan, M. A. J. Phys. Chem. A 2004, 108, 6605. a splitting here of about $42 \mathrm{~cm}^{-1}$, consistent with our measured value of about $46 \mathrm{~cm}^{-1}$. The eclipsed conformation is predicted to have a splitting of about $20 \mathrm{~cm}^{-1}$. It is tempting, therefore, to conclude that our data is more consistent with the staggered conformation. However, we must bear in mind that the IR-REMPD methodology can itself lead to vibrational band shifts of this same order of magnitude that may be modedependent. This, taken together with the widths of the features in our spectrum, suggests that a firm conclusion on this issue is really beyond the present capability of the experiment. An added complication is the temperature of the ions. Because the energy difference between eclipsed and staggered conformations is small, there will likely be a superposition of these conformations present in the beam at any finite temperature. Indeed, it is conceivable that there could be dynamic rotation about the $\mathrm{C}_{6}$ axis at higher temperatures. It is impossible to estimate the temperature resulting from the photoionization process here, and therefore, an in-depth examination of conformation is likely premature under these conditions. However, such studies may become relevant when ions can be produced in colder sources.

\section{Conclusion}

A variety of transition-metal mono- and dibenzene complexes have been studied for the first time with infrared photodissociation spectroscopy in the gas phase. Corresponding studies have investigated these complexes with density functional theory calculations, providing a systematic investigation of geometry, bond energies, and electronic structure for the series of firstrow transition metals. Vibrational spectra exhibit sharp bands in the fingerprint region that can be compared to the spectra measured for condensed-phase complexes produced by conventional synthesis. Through the interaction with theory, these vibrational bands can be assigned and related to corresponding vibrational motions in the free benzene molecule. In the region of this experiment $\left(600-1700 \mathrm{~cm}^{-1}\right)$, vibrational bands are observed for the $v_{11}, v_{18}$, and $v_{19}$ modes that are IR-active in benzene, as well as for the $v_{1}$ mode that is IR-forbidden in benzene. The strong $v_{11}$ and $v_{19}$ bands are observed for essentially all complexes, while the $v_{18}$ and $v_{1}$ bands are seen mostly for the earlier transition metals. In the same way seen previously for dibenzene sandwich complexes in the condensed phase, the systems studied here exhibit red shifts for the $v_{19}$ vibrational bands and blue shifts for the $v_{11}$ vibrational bands. The $v_{19}$ mode, which was predicted previously as an indicator for the degree of charge transfer in these complexes, exhibits a systematic trend with larger red shifts for the earlier transition metals. Likewise, we find a similar trend for the intensities of the $v_{1}$ bands, which are also stronger for the earlier transition metals. Theory agrees with the qualitative trends revealed by these spectra, but the agreement on vibrational band positions is not highly quantitative.

The vibrational structure in these complexes was investigated together with theoretical predictions to determine if this would be a reliable indicator for different spin multiplicities and/or conformations (staggered versus eclipsed) in these complexes. Clear differences were found by theory for the vibrational structure in electronic states with different multiplicities. However, in selected systems where exact comparison was possible (dibenzene complexes of vanadium and titanium), the measured spectra do not agree with the patterns predicted for the lowest-energy electronic states. It is conceivable that this 
discrepancy arises because the ions are produced in excited states, and therefore, different ion formation methods need to be investigated to clarify this. However, a more serious concern, which also warrants further investigation, is that DFT fails to identify the lowest-energy electronic state in some of these openshell complexes. The vibrational spectra for different conformations were found to be so similar that we could not distinguish these with the present experimental resolution.

These data represent perhaps the most comprehensive study yet performed on the spectroscopy and electronic structure of mono- and dibenzene transition-metal ion complexes. It is clear from this study that IR spectroscopy has the potential to answer fundamental questions about the geometries and electronic structures of these complexes. Some striking patterns have been revealed here for the first time, involving the red shift of the $v_{19}$ bands and the intensities of the $v_{1}$ bands. When these experiments can be extended to other regions of the IR spectrum (e.g., $\mathrm{M}-\mathrm{bz}$ stretch; $\mathrm{C}-\mathrm{H}$ stretch) and improved with regard to ion formation mechanism and spectroscopic resolution, further insights into the structure and bonding of these classic organometallic complexes can be anticipated.
Acknowledgment. We gratefully acknowledge support from the "Stichting voor Fundamenteel Onderzoek der materie" (FOM) and the "Nederlandse Organisatie voor Wetenschappelijk Onderzoek (NWO)". M.A.D. acknowledges generous support for this work from the National Science Foundation (CHE0244143). The work at Sandia was supported by the Division of Chemical Sciences, Geosciences, and Biosciences, the Office of Basic Energy Sciences of the U.S. Department of Energy. Sandia is a multiprogram laboratory operated by Sandia Corporation, a Lockheed Martin Company, for the U.S. Department of Energy's National Nuclear Security Administration under Contract No. DE-AC04-94-AL85000.

Supporting Information Available: Complete tables containing the theoretical results described in this article (Excel). This includes listings of all the vibrational frequencies and band intensities for each complex in each of its electronic states. This material is available free of charge via the Internet at http://pubs.acs.org.

JA0477165 